\title{
Statins Do Not Reduce Atrial Fibrillation After Cardiac Valvular Surgery: A Single Centre Observational Study
}

\author{
R. J. Folkeringa • R. G. Tieleman • J. G. Maessen • \\ M. H. Prins • R. Nieuwlaat $\cdot$ H. J. G. M. Crijns
}

Published online: 16 December 2010

(C) The Author(s) 2010. This article is published with open access at Springerlink.com

\begin{abstract}
Introduction Statins may theoretically reduce postoperative atrial fibrillation (AF) in patients after cardiac valvular surgery due to preservation of endothelial function and antiischaemic, anti-inflammatory and anti-remodelling effects. Methods Two hundred seventy-two patients who underwent cardiac workup and subsequently cardiac valvular surgery without $\mathrm{AF}$ and concomitant coronary artery bypass grafting (CABG) at our hospital were selected. Preoperative drug use and postoperative AF were recorded. $\mathrm{AF}$ was defined as any episode of AF longer than $10 \mathrm{~s}$. In
\end{abstract}

R. J. Folkeringa $(\bowtie)$

Department of Cardiology, Medisch Centrum Leeuwarden,

Henry Dunantweg 2,

8934 AD, Leeuwarden, the Netherlands

e-mail: richard.folkeringa@znb.nl

R. G. Tieleman

Department of Cardiology, Martini Hospital,

Groningen, the Netherlands

J. G. Maessen

Department of Cardiothoracic Surgery,

University Hospital Maastricht,

Maastricht, the Netherlands

\section{H. Prins}

Department of Clinical Epidemiology and Medical Technology Assessment, University Hospital Maastricht,

Maastricht, the Netherlands

R. Nieuwlaat

Population Health Research Institute, McMaster University, Hamilton, Canada

H. J. G. M. Crijns

Department of Cardiology, University Hospital Maastricht, Maastricht, the Netherlands addition, results from echocardiography and blood samples were retrieved.

Results Baseline characteristics were as follows: mean age was $65 \pm 11$ years, $142(52 \%)$ patients were male, $189(70 \%)$ had undergone aortic valve surgery and the mean left ventricular ejection fraction was $57 \pm 12 \%$. Statins were used by 79 patients (29\%). Statin users, more often, had a prior percutaneous coronary intervention $(25 \%$ vs $9 \%, p<0.001)$ or CABG $(24 \%$ vs $4 \%, p<0.001)$, diabetes mellitus $(22 \%$ vs $5 \%, p<0.001)$ and more often used $\beta$-blockers $(51 \%$ vs $24 \%$, $p<0.001)$. Patients in the non-statin group more often had surgery on more than one valve $(10 \%$ vs $3 \%, p=0.043)$ and had a higher cholesterol level $(222 \pm 48$ vs $190 \pm 43 \mathrm{mg} / \mathrm{dl}$, $p<0.001)$. Postoperative AF occurred in 54\% (43/79) of the patients with and in 55\% (106/193) of the patients without statins $(p=0.941)$. There was also no difference in the timing of onset of AF or duration of hospital stay.

Conclusion In this observational study, statin use was not associated with a reduced incidence of AF in patients after cardiac valvular surgery.

Keywords Cardiac surgery $\cdot$ Atrial fibrillation $\cdot$ Statin

\section{Introduction}

Cardiac valvular surgery has excellent long-term survival results and is the treatment of choice in patients with severe valvular disease [1]; however, postsurgical morbidity remains high. Frequent complications such as atrial fibrillation (AF) may worsen prognosis, prolong hospital stay and increase medical costs. Therefore, it is important to improve strategies to reduce postsurgical morbidity. In this respect, statins are interesting drugs. Statins have shown to reduce morbidity and mortality in a broad range of patients 
with cardiovascular diseases [2, 3]. In addition to cholesterol-lowering properties, experimental and clinical data suggest that statins may also exhibit antiinflammatory, endothelial protective, antioxidative and anti-remodelling effects [4-8]. Indeed, statins may prevent AF after coronary artery bypass grafting (CABG) surgery $[9,10]$; however, this does not prove a pleiotropic effect since this may be caused by the vasoprotective effects of statins and reduction of ischaemia, thereby preventing AF. Ischaemia due to coronary artery disease is less likely to play a major role after valvular surgery; however, few data exist on the possible protective effects of statins after cardiac valvular surgery. Therefore, we hypothesise that statins may reduce AF and shorten hospital stay after cardiac valvular surgery.

\section{Methods}

\section{Study Population}

In retrospect, 272 consecutive patients undergoing cardiac valvular surgery in our department between July 1996 and March 2004 were identified. Patients with AF on the day of surgery or with concomitant CABG were excluded to avoid treatment bias due to symptomatic coronary artery disease. Patients referred from other hospitals were excluded because of incomplete pre- and postoperative data for this observational study. After these exclusions, our study cohort consisted of 272 patients who underwent cardiac valvular surgery without concomitant $\mathrm{CABG}$ in our hospital during this period. Patients with prior cardiac surgery, including CABG, were not excluded.

\section{Data Collection}

Echocardiographic data were collected from our routine clinical database. In addition, admission levels of haemoglobin and creatinine were retrieved as well as the maximal creatinine phosphokinase in the first $24 \mathrm{~h}$ after surgery.

Each medical chart was reviewed for preoperative medication, including statins, $\beta$-adrenergic receptor blockers, angiotensin-converting enzyme inhibitors, angiotensin II receptor blockers and antiarrhythmic drugs. These drugs needed to be prescribed for at least 1 week prior to surgery if a drug was considered to be given.

\section{Atrial Fibrillation}

AF was defined as any episode of AF longer than $10 \mathrm{~s}$. Rhythm data during admission were attained by retrieving all electrocardiographic and Holter recordings from the medical chart. Data on previous episodes of AF were attained from the chart and from our clinical ECG database.

\section{Statistical Analysis}

All statistics were performed by SPSS version 11.0. Results are presented as the mean value $\pm \mathrm{SD}$ for continuous variables and as the percentage of total patients for categorical data. The independent samples $t$ test was used for comparison of continuous variables and the $\chi^{2}$ test for categorical variables. Potential predictors of hospital stay were related to the duration of stay in days using linear regression analysis. For this purpose, the duration was lognormalised since it was skewed.

Cholesterol levels were missing in $41(15 \%)$ patients. Therefore, we first assessed whether the missing status was statistically informative using a dummy variable. Since this was not the case, the missing values were imputed using 'the mean value of the whole group' approach. Multivariable logistic regression was performed to test whether statin prescription was associated with postoperative AF occurrence when correcting for potential confounders. Variables entered in the model were age, sex, New York Heart Association class, previous AF, history of percutaneous coronary interventions (PCI), history of CABG, prior valvular surgery, pulmonary hypertension, haemoglobin level, atrial size, the use of $\beta$-blockers, antiarrhythmic drugs, aortic valve surgery, combined surgery on more than one valve and the use of statin and the propensity score. The effect of statin prescription on occurrence of postoperative AF might be biased by the absence of randomisation in this observational study, and therefore a propensity score was added to the multivariate logistic regression model in order to correct as well as possible for the propensity of a physician to select patients for prescribing statins. Individual propensity scores were calculated by means of backward deletion logistic regression (see "Methods"). The propensity score was added as a continuous variable to the multivariable logistic regression analysis. The variable for statin prescription and its propensity score were kept at all times in the model regardless of their significance, since this was the main effect we wanted to test.

\section{Results}

The mean age of the patients was $65 \pm 11$ years, the mean left ventricular ejection fraction was $57 \pm 12 \%, 142$ patients $(52 \%)$ were male and $20 \%$ had a history of AF (Table 1 ). Aortic valve replacement was performed in $189(70 \%)$ 
Table 1 Baseline characteristics and comparison between statin users and non-statin users
NYHA New York Heart Association, $C O P D$ chronic obstructive pulmonary disease, $A C E-I$ angiotensin-converting enzyme inhibitor or angiotensin II receptor blocker, $A A D$ class I or III antiarrhythmic drugs, $E C C$ extracorporal circulation clamp time, $A C C$ aorta circulation clamp, $L V E F$ left ventricular ejection fraction

${ }^{\text {a }} 25$ th and 75 th percentiles

${ }^{\mathrm{b}}$ Mann-Whitney $U$ results

\begin{tabular}{|c|c|c|c|c|}
\hline & $\begin{array}{l}\text { All } \\
N=272\end{array}$ & $\begin{array}{l}\text { Statin users } \\
N=79\end{array}$ & $\begin{array}{l}\text { Non-statin users } \\
N=193\end{array}$ & $P$ \\
\hline Age (years) & $65 \pm 11$ & $65 \pm 11$ & $65 \pm 11$ & 0.510 \\
\hline Male $(\%)$ & $142(52)$ & $41(52)$ & $101(52)$ & 0.948 \\
\hline \multicolumn{5}{|l|}{ Previous history, $n(\%)$} \\
\hline NYHA I & $37(14)$ & $8(11)$ & $29(15)$ & \\
\hline NYHA II & $55(21)$ & $16(22)$ & $39(21)$ & \\
\hline NYHA III & $146(56)$ & $41(56)$ & $105(56)$ & \\
\hline NYHA IV & $23(9)$ & $8(11)$ & $15(8)$ & 0.728 \\
\hline $\mathrm{AF}$ & $54(20)$ & $17(22)$ & $37(19)$ & 0.659 \\
\hline PCI & $37(14)$ & $20(25)$ & $17(9)$ & $<0.001$ \\
\hline CABG & $26(10)$ & $19(24)$ & $7(4)$ & $<0.001$ \\
\hline Valve surgery & $23(9)$ & $10(13)$ & $13(7)$ & 0.111 \\
\hline Diabetes & $27(10)$ & $17(22)$ & $10(5)$ & $<0.001$ \\
\hline COPD & $31(12)$ & $8(11)$ & $23(12)$ & 0.743 \\
\hline Hypertension & $110(40)$ & $37(47)$ & $73(38)$ & 0.169 \\
\hline Pulmonary hypertension & $107(41)$ & $30(39)$ & $77(42)$ & 0.641 \\
\hline \multicolumn{5}{|l|}{ Laboratory } \\
\hline Haemoglobin $(\mathrm{mmol} / \mathrm{l})$ & $8.4 \pm 1.0$ & $8.4 \pm 1.0$ & $8.4 \pm 1.0$ & 0.741 \\
\hline Creatinine $(\mu \mathrm{mol} / \mathrm{l})$ & $98(78-104)^{\mathrm{a}}$ & $106(74-107)^{\mathrm{a}}$ & $94(79-103)^{\mathrm{a}}$ & $0.604^{\mathrm{b}}$ \\
\hline Cholesterol (mg/dl) & $212 \pm 49$ & $190 \pm 43$ & $222 \pm 48$ & $<0.001$ \\
\hline \multicolumn{5}{|l|}{ Echocardiography } \\
\hline Left atrial size $(\mathrm{mm})$ & $48 \pm 8$ & $49 \pm 7$ & $48 \pm 8$ & 0.894 \\
\hline LVEF (\%) & $57 \pm 12$ & $56 \pm 11$ & $58 \pm 12$ & 0.349 \\
\hline \multicolumn{5}{|l|}{ Drugs, $n(\%)$} \\
\hline ACE-I & $127(47)$ & $41(52)$ & $86(45)$ & 0.271 \\
\hline Beta-blocker & $87(32)$ & $40(51)$ & $47(24)$ & $<0.001$ \\
\hline $\mathrm{AAD}$ & $44(16)$ & $12(15)$ & $32(17)$ & 0.777 \\
\hline \multicolumn{5}{|l|}{ Surgery, $n(\%)$} \\
\hline Emergency & $12(4)$ & $3(4)$ & $9(5)$ & 0.752 \\
\hline Aortic valve & $189(70)$ & $57(72)$ & $132(68)$ & 0.541 \\
\hline Mitral valve & $78(29)$ & $19(24)$ & $59(31)$ & 0.280 \\
\hline$>1$ valve & $21(8)$ & $2(3)$ & $19(10)$ & 0.043 \\
\hline Mechanical prosthesis & $201(75)$ & $62(81)$ & $139(72)$ & 0.166 \\
\hline ECC time (min) & $105 \pm 42$ & $102 \pm 35$ & $106 \pm 45$ & 0.430 \\
\hline ACC time (min) & $75 \pm 29$ & $70 \pm 22$ & $77 \pm 31$ & 0.075 \\
\hline
\end{tabular}

patients, mitral valve repair or replacement in $78(29 \%)$ patients and $21(8 \%)$ patients had surgery on more than one valve. A total of $201(75 \%)$ patients received a mechanical valve. Table 1 shows the baseline characteristics and a comparison of statin vs non-statin users.

Statin users more often had diabetes mellitus $(22 \%$ vs $5 \%, p<0.001)$ and more often used $\beta$-blockers $(51 \%$ vs $24 \%, p<0.001)$. In addition, these patients more often had a history of PCI $(25 \%$ vs $9 \%, p<0.001)$ or CABG $(24 \%$ vs $4 \%, p<0.001)$. Patients in the non-statin group more often had surgery on more than one valve $(10 \%$ vs $3 \%, p=$ $0.043)$, and a higher cholesterol level $(222 \pm 48$ vs $190 \pm$ $43 \mathrm{mg} / \mathrm{dl}, p<0.001)$.
Statin Use and Postoperative Atrial Fibrillation

AF occurred after a mean of $4.0 \pm 3.7$ days in patients without and after $3.7 \pm 3.3$ days in patients with a statin ( $p=$ 0.615). Table 2 shows the univariate differences in characteristics between patients who had postoperative AF vs the ones without AF. Patients with postoperative AF were older and more often male. In addition, they more often had a history of PCI or pulmonary hypertension, had a lower haemoglobin level, a larger left atrium, more often used an antiarrhythmic drug and were more often operated on more than one valve. AF occurred in 149/272 (55\%) of the patients undergoing surgery in sinus rhythm. Forty- 
Table 2 Comparison of patients with and without $\mathrm{AF}$
NYHA New York Heart Association, COPD chronic obstructive pulmonary disease, $A C E-I$ angiotensin-converting enzyme inhibitor or angiotensin II receptor blocker, $A A D$ class I or III antiarrhythmic drugs, ECC extracorporal circulation clamp time, $A C C$ aorta circulation clamp, $L V E F$ left ventricular ejection fraction

a 25 and 75 percentiles

${ }^{\mathrm{b}}$ Mann-Whitney $U$ results

\begin{tabular}{|c|c|c|c|}
\hline & $\begin{array}{l}\text { No AF } \\
N=123\end{array}$ & $\begin{array}{l}\mathrm{AF} \\
N=149\end{array}$ & $P$ \\
\hline Age (years) & $63 \pm 12$ & $67 \pm 10$ & 0.002 \\
\hline Male, $n(\%)$ & $48(39)$ & $82(55)$ & 0.009 \\
\hline \multicolumn{4}{|l|}{ Previous history, $n(\%)$} \\
\hline NYHA I & $24(21)^{\mathrm{a}}$ & $13(9)$ & \\
\hline NYHA II & $20(17)$ & $35(24)$ & \\
\hline NYHA III & $64(55)$ & $82(57)$ & \\
\hline NYHA IV & $9(8)$ & $14(10)$ & 0.047 \\
\hline $\mathrm{AF}$ & $12(10)$ & $42(28)$ & $<0.001$ \\
\hline PCI & $19(15)$ & $12(8)$ & 0.056 \\
\hline CABG & $16(13)$ & $10(7)$ & 0.079 \\
\hline Valve surgery & $29(10)$ & $11(13)$ & 0.198 \\
\hline Diabetes & $10(8)$ & $17(11)$ & 0.368 \\
\hline COPD & 17 (14) & $14(10)$ & 0.219 \\
\hline Hypertension & $47(38)$ & $63(42)$ & 0.496 \\
\hline Pulmonary hypertension & $36(32)$ & $71(49)$ & 0.006 \\
\hline \multicolumn{4}{|l|}{ Laboratory } \\
\hline Haemoglobin $(\mathrm{mmol} / \mathrm{l})$ & $8.6 \pm 0.9$ & $8.3 \pm 1.1$ & 0.019 \\
\hline Creatinine $(\mu \mathrm{mol} / \mathrm{l})$ & $104(78-106)^{\mathrm{a}}$ & $92(78-102)^{\mathrm{a}}$ & $0.947^{\mathrm{b}}$ \\
\hline Cholesterol (mg/dl) & $211 \pm 51$ & $212 \pm 47$ & 0.781 \\
\hline \multicolumn{4}{|l|}{ Echocardiography } \\
\hline Left atrial size $(\mathrm{mm})$ & $47 \pm 8$ & $49 \pm 3$ & 0.048 \\
\hline LVEF (\%) & $57 \pm 13$ & $57 \pm 11$ & 0.824 \\
\hline \multicolumn{4}{|l|}{ Drugs, $n(\%)$} \\
\hline ACE-I & $53(43)$ & $74(50)$ & 0.279 \\
\hline Beta-blocker & $33(27)$ & $54(36)$ & 0.098 \\
\hline Statin & $36(29)$ & $43(29)$ & 0.941 \\
\hline $\mathrm{AAD}$ & $13(11)$ & $31(21)$ & 0.023 \\
\hline \multicolumn{4}{|l|}{ Surgery, $n(\%)$} \\
\hline Emergency & $7(6)$ & $5(3)$ & 0.351 \\
\hline Aortic valve & $92(75)$ & $97(65)$ & 0.084 \\
\hline Mitral valve & $32(26)$ & $46(31)$ & 0.378 \\
\hline$>1$ valve & $5(4)$ & $16(11)$ & 0.037 \\
\hline Mechanical prosthesis & $95(77)$ & $106(73)$ & 0.384 \\
\hline ECC time (min) & $103 \pm 43$ & $106 \pm 41$ & 0.554 \\
\hline ACC time (min) & $74 \pm 30$ & $76 \pm 28$ & 0.668 \\
\hline
\end{tabular}

three out of 79 patients (54\%) taking statins developed AF, compared with 106/193 (55\%) patients not taking these cholesterol-lowering drugs $(p=0.941)$. The incidence of AF in patients without any previous episode of $\mathrm{AF}$ was $49 \%$ in non-statin users vs $50 \%$ in statin users, $(p=0.864)$.

In the multivariate analysis, statin use was not associated with AF occurrence $(p=0.345)$. Significant predictors of postoperative $\mathrm{AF}$ were age, a previous episode of $\mathrm{AF}$, a history of CABG and pulmonary hypertension (Table 3). The mean propensity score for statin use was 0.27 (25th and 75 th percentiles, 0.05 and 0.42 , respectively).
Table 3 Multivariate analysis with propensity scores for statin

\begin{tabular}{lll}
\hline & $P$ value & OR $(95 \%$ CI $)$ \\
\hline Age & 0.002 & $1.05(1.017-1.074)$ \\
Previous AF & 0.001 & $4.55(1.905-10.856)$ \\
Previous CABG & 0.029 & $0.24(0.067-0.867)$ \\
Pulmonary hypertension & 0.022 & $1.98(1.102-3.557)$ \\
Statin & 0.345 & $1.49(0.651-3.403)$ \\
\hline
\end{tabular}


Interactions were observed between statin and haemoglobin levels $(p=0.024)$; however, statin therapy was still not predictive of postoperative $\mathrm{AF}$ in patients with a mean haemoglobin of $\leq 8.41 \mathrm{mmol} / 1 \quad(p=0.914)$ vs those with levels $>8.41 \mathrm{mmol} / 1(p=0.552)$. Other interactions were noted between age and sex $(p=0.013)$ and between history of AF and surgery on more than one valve $(p=$ 0.012 ).

\section{Statin Use and Length of Hospital Stay and Mortality}

The mean length of hospital stay was 13.9 days (25th and 75th percentiles, 7 and 18 days, respectively). The use of statins was not associated with shorter hospitalisation, $4 \%$ decrease in hospital stay duration, $95 \% \mathrm{CI}-18 \pm 12 \%$ ( $p=$ $0.602)$. In-hospital mortality was $4 \%$ in both statin and nonstatin users $(p=0.971)$.

\section{Subgroup Analysis}

The most powerful predictor of postoperative $\mathrm{AF}$ is a history of AF. One may argue that if statins were not able to prevent AF prior to surgery, they may also not prevent AF after surgery. Therefore, another subanalysis was performed in patients without a history of AF. By excluding these, $218(80 \%)$ patients remained in the model, of which $62(28 \%)$ used a statin and $107(49 \%)$ developed AF. Multivariate predictors of postsurgical AF were age $(p=0.015)$ and haemoglobin levels prior to surgery $(p=0.035)$. Still, the use of a statin was not associated with $\mathrm{AF}(p=0.392)$.

Another subanalysis was performed in patients without previous PCI or CABG, leaving a total of $226(83 \%)$ patients. In this subgroup, $52(23 \%)$ used a statin and 124 patients (55\%) developed AF. When excluding patients with prior $\mathrm{CABG}$, none of the patients undergoing prior valve surgery remained. Except for this, the same variables as in the main model were entered in the multivariate analysis, as all had univariate $p$ values $<0.10$. Multivariate predictors of postsurgical AF were age $(p=0.005)$ and prior AF $(p=0.001)$. The use of statin was not associated with $\operatorname{AF}(p=0.782)$. In this model, pulmonary hypertension did not reach significance $(p=$ $0.074)$.

\section{Discussion}

This study shows that treatment with statins is not associated with a reduction of AF in patients undergoing valvular surgery. In line with these observations, statins were not associated with a shorter hospital stay.

\section{Statins and Postoperative AF}

Risk factors for atherosclerotic disease such as hypertension and age are associated with an increased risk for AF. This suggests an association between $\mathrm{AF}$ and atherosclerotic vascular disease [11]. In contrary to most studies, we excluded concomitant CABG surgery to minimise the effect of atherosclerotic vascular disease. Thus far, several studies after thoracic surgery have shown conflicting results. Four observational studies in patients after CABG and noncardiac thoracic surgery have shown a decreased postoperative $\mathrm{AF}$ incidence with the use of a statin [12-15]. In addition, a randomised trial of 200 patients showed that in patients after CABG surgery, AF was reduced by almost $40 \%$ with atorvastatin starting 1 week before the operation $(35 \%$ vs $57 \%, p=0.003$ ) [9]. This is in accordance with the finding that statins may reduce AF in patients with symptomatic coronary artery disease [10]. Such an effect seems plausible since statins can prevent atherosclerosis and its consequences; however, these data are in conflict with a large retrospective cohort analysis in 4,044 patients in which statins were not associated with AF reduction after CABG [16].

In concert with this, we found no relation between statin treatment and postoperative $\mathrm{AF}$ in patients after valvular surgery. Discrepancies between studies may relate to the type of patients. It may be assumed that patients with coronary artery disease respond better to statins than patients undergoing valvular surgery. In addition, the severe valvular disease has already led to a substrate for $\mathrm{AF}$, irrespective of the inflammatory effects caused by the operation. This is illustrated by a higher incidence of AF after valvular surgery compared with CABG surgery. In the latter, postoperative $\mathrm{AF}$ is more likely to depend on excess triggers caused by the inflammatory response to surgery. Therefore, reduction of inflammation by statins may decrease the incidence of $\mathrm{AF}$ in the $\mathrm{CABG}$ patients, but not after valvular surgery.

Our patients may differ significantly from previous studies since they had a high postoperative AF rate suggesting significant remodelling and inflammation not suppressible by statins.

\section{Mechanisms by Which Statins May Prevent AF}

Theoretically, statins may reduce postoperative AF by several mechanisms. Firstly, statins may exert systemic anti-inflammatory effects by reducing $\mathrm{T}$ cell activation, thereby reducing inflammatory cytokine production such as IL-6 and C-reactive protein (CRP) [17, 18]. A high CRP level is a risk factor for cardiovascular events, including the development and maintenance of $\mathrm{AF}[4,19-21]$. $\mathrm{AF}$ incidence peaks $2-3$ days after thoracic surgery when 
CRP levels are highest. In addition, higher CRP levels are associated with higher AF burden [20]. Further evidence of an inflammatory basis of AF is supported by atrial biopsies, showing that atrial myocarditis is frequent in lone AF [21]. Inflammation may lead to AF by slowing atrial conduction, thereby facilitating re-entry $[22,23]$.

Other reported beneficial effects of statins to prevent $\mathrm{AF}$ are their antioxidant, anti-remodelling properties, modification of neurohormonal activation of the renin-angiotensin and the autonomic nervous system, direct antiarrhythmic effects by cell membrane ion channel stabilisation, direct protection of the ischaemic myocardium or modulation of the extracellular matrix.

\section{Study Limitations}

We performed an observational study, so we did not randomise our patients. This is reflected by the differences in baseline characteristics. Although the statin group more often had diabetes mellitus, the non-statin group more often had surgery on more than one valve and a higher cholesterol level; however, by adding propensity scores to the multivariate analysis, we corrected as well as possible for the differences between the statin and non-statin users.

In addition, the sample size may be too small for drawing firm conclusions; however, no small trend in favour of statin use was seen. In the univariate analysis, a statin was used in $29 \%$ of patients with and without AF ( $p=$ 0.941 in univariate analysis). Therefore, it is unlikely that sample size precluded significance, although it cannot be excluded.

All patients in the statin group used a statin for at least 1 week. We did not analyse duration, dosing and the different types of statins. Despite these drawbacks, our study does not support the hypothesis that pleiotropic effects of statins may decrease AF in this population.

\section{Conclusion}

Statins are not associated with a decreased incidence of AF after cardiac valvular surgery. Our results conflict with most reports in patients with vascular disease in which statins may be beneficial. Further research should focus on the role of statins in subjects who are not vascularly compromised.

Acknowledgment This study was supported by grant 2003B103 of the Netherlands Heart Foundation.

Open Access This article is distributed under the terms of the Creative Commons Attribution Noncommercial License which permits any noncommercial use, distribution, and reproduction in any medium, provided the original author(s) and source are credited.

\section{References}

1. Bonow RO, Carabello B Jr, et al. ACC/AHH guidelines for the management of patients with valvular heart disease. Executive summary. A report of the American College of Cardiology/ American Heart Association Task Force on practice guidelines (Committee on management of patients with valvular heart disease). Circulation. 1998;98:1949-84.

2. Heart Protection Study Collaborative Group. MRC/BHF Heart protection study of cholesterol lowering with simvastatin in 20536 high-risk individuals: a randomised placebo-controlled trial. Lancet. 2002;360:7-22.

3. Sever PS, Dahlöf B, Poulter NR, et al. Prevention of coronary and stroke events with atorvastatin in hypertensive patients who have average or lower-than-average cholesterol concentrations, in the Anglo-Scandinavian Cardiac Outcomes Trial-Lipid lowering arm (ASCOTT-LLA): a multicentre randomised controlled trial. Lancet. 2003;361:1149-58.

4. Ridker PM, Rifai N, Clearfeld M, et al. Measurement of C-reactive protein for the targeting of statin therapy in the primary prevention of acute coronary events. N Engl J Med. 2001;344:1959-65.

5. Patel R, Nagueh SF, Tsybouleva N, et al. Simvastatin induces regression of cardiac hypertrophy and fibrosis and improves cardiac function in a transgenic rabbit model of human hypertrophic cardiomyopathy. Circulation. 2001;104:317-24.

6. Su SF, Hsiao CL, Chu CW, Lee BC, Lee TM. Effects of pravastatin on left ventricular mass in patients with hyperlipidemia and essential hypertension. Am J Cardiol. 2000;86:5148.

7. Oi S, Haneda T, Osaki J, et al. Lovastatin prevents angiotensin-II induced cardiac hypertrophy in cultured neonatal rat heart cells. Eur J Pharmacol. 1999;376:139-48.

8. Indolfi C, Di Lorenzo E, Perrino C, et al. Hydroxymethylglutaryl coenzyme A reductase inhibitor simvastatin prevents cardiac hypertrophy induced by pressure overload and inhibits p21ras activation. Circulation. 2002;106:2118-24.

9. Patti G, Chello M, Candura D, et al. Randomized trial of atorvastatin for reduction of postoperative atrial fibrillation in patients undergoing cardiac surgery. Results of the ARMYDA-3 (atorvastatin for reduction of myocardial dysrhythmia after cardiac surgery) study. Circulation. 2006;114:1455-61.

10. Dotani MI, Elnicki M, Jain AC, Gibson CM. Effect of preoperative statin therapy and cardiac outcomes after coronary artery bypass grafting. Am J Cardiol. 2000;86:1128-30.

11. Fauchier L, Pierre B, De Labriolle A, et al. Antiarrhythmic effect of statin therapy and atrial fibrillation. A meta-analysis of randomized controlled trials. J Am Coll Cardiol. 2008;51:828-35.

12. Ozaydin M, Gogan A, Varol E, et al. Statin use before bypass surgery decreases the incidence and shortens the duration of postoperative atrial fibrillation. Cardiology. 2007;107:117-21.

13. Marin F, Pascual DA, Roldan V, et al. Statins and postoperative risk of atrial fibrillation following coronary artery bypass grafting. Am J Cardiol. 2006;97:55-60.

14. Mariscalco G, Lorusso R, Klersy C, et al. Observational study on the beneficial effect of preoperative statins in reducing atrial fibrillation after coronary surgery. Ann Thorac Surg. 2007;84:1158-65.

15. Amar D, Zhang H, Heerdt PM, et al. Statin use is associated with a reduction in atrial fibrillation after noncardiac thoracic surgery independent of C-reactive protein. Chest. 2005;128:3421-7.

16. Virani SS, Nambi V, Razavi M, et al. Preoperative statin therapy is not associated with a decrease in the incidence of postoperative atrial fibrillation in patients undergoing cardiac surgery. Am Heart J. 2008;155:541-6. 
17. Ray KK, Cannon CP. The potential relevance of the multiple lipid-independent (pleiotropic) effects of statins in the management of acute coronary syndromes. J Am Coll Cardiol. 2005;46:1425-33.

18. Kwak B, Mulhaupt F, Myit S, Mach F. Statins as a newly recognized type of immunomodulator. Nat Med. 2000;6:1399402.

19. Gaudino M, Andreotti F, Zamparelli R, et al. The $-174 \mathrm{G} / \mathrm{C}$ interleukin-6 polymorphism influences postoperative interleukin-6 levels and postoperative atrial fibrillation. Is atrial fibrillation an inflammatory complication? Circulation. 2003;108 Suppl I:II1959.
20. Chung MK, Martin DO, Sprecher D, et al. C-reactive protein elevation in patients with atrial arrhythmias. Inflammatory mechanisms and persistence of atrial fibrillation. Circulation. 2001;104:2886-91.

21. Frustaci A, Chimenti C, Bellocci F, et al. Histological substrate of atrial biopsies in patients with lone atrial fibrillation. Circulation. 1997;96:1180-4.

22. Echahidi N, Pibarot P, O'Hara G, Mathieu P. Mechanisms, prevention, and treatment of atrial fibrillation after cardiac surgery. J Am Coll Cardiol. 2008;51:793-801.

23. Isaac TT, Dokainish H, Lakkis NM. Role of inflammation in initiation and perpetuation of atrial fibrillation. J Am Coll Cardiol. 2007;50:2021-8. 